\title{
Technical study of the effect of laser engraving using uArm swift pro robot
}

\author{
Soumen Mondal, Ajoy Kumar Dutta
}

Department of Production Engineering, Jadavpur University, India

\begin{tabular}{l} 
Article Info \\
\hline Article history: \\
Received Mar 10, 2021 \\
Revised Apr 12, 2021 \\
Accepted May 16, 2021 \\
\hline
\end{tabular}

Keywords:

Laser engraving

Laser nozzle

uArm Studio 1.1.22 software

uArm swift pro robot

Wooden pitch board

\begin{abstract}
Laser engraving is the most non-traditional and efficient working method in the machining of materials of different geometry as compared to conventional methods. The main objective of this study is to determine the impact of uArm swift pro robot operated laser engraving process on a wooden pitch board piece. However, the robot was connected with uArm Studio 1.1.22 software to perform laser engraving operation. For this purpose the effect of process parameters like spot diameter and depth of penetration were investigated with different working length of the robot end effector, measured from wooden pitch board base. Experimental observation method was used to investigate the formation of deep and light engraving pattern on the pitch board surface by measuring penetration depth and spot diameter in suitable condition. The result obtained from the experiment and statistical parameters showed a new dimension to find a suitable working length of the robot assisted laser nozzle where the laser penetration effect was clearly perceptible for the wooden material.
\end{abstract}

This is an open access article under the CC BY-SA license.

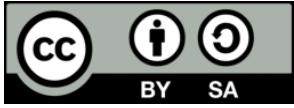

Corresponding Author:

Soumen Mondal

Department of Production Engineering

Jadavpur University

188, Raja Subodh Chandra Mallick Rd, Jadavpur, Kolkata, West Bengal-700032, India

Email: msoumen.16@gmail.com

\section{INTRODUCTION}

In contrast to previous years, lasers were largely used in the handicraft industry not only for cutting, incising, surface treatment, cleaning of solid wood and wood composites but also marking, engraving attractive wooden items [1]-[8]. Presently laser sources are defined in fem to second which has been useful to metallic, ceramic and non-metallic materials in various machining processes such as labeling, scribing, selective ablation and engraving [9]-[14]. Lasers are mainly monochromatic non-contact forms with greater repeatability, scanning speed, versatility and automation. Laser beams alter the chemical composition of irradiated wood surfaces [15], [16]. Microscopic studies indicate that treating wood surfaces with a laser beam would make the surface smoother since the cells melt down to a depth of several micrometers without direct carbonization [17]. A laser can cause similar changes in other natural and synthetic polymer materials in relation to degradation, de-polymerization, and carbonization processes in various types of organic macromolecules [18]. Leone et al. [19] showed the popularity of laser engraving technology and investigating about the surface layers under the ones that are burned away and clearly depicted the effect of temperature, heating time of laser beam on the laser power. It's essential to choose optimal process parameters like laser beam power, spot diameter, wavelength on the basis of material type and dimensional stability [20], [21]. Another disadvantage of wood laser engraving is the materials in homogeneity and anisotropy. As a result, wood materials have a fibrous structure with varying fibre dimensions and densities 
that communicate with the laser beam in different modes [20]-[23] which difficult to make smooth or exact engrave surface. Laser engraving, which is a subset of laser marking, is basically a permanent and less offensive method, similar to laser beam milling. A high-intensity laser beam passes across the surface in this method, following the preferred geometry. The amount of laser energy that determines the rate of material removal by contact with the material's surface is also influenced by laser strength, scanning speed and beam overlap rate [24]-[26]. Kasman [26] proposed that the laser scan speed, which is increased by raising local temperature indicates the interaction time between the laser beams and such of condition signification amount of material vaporizes as its temperature exceeds the limiting stage results formation of crater. The contact time between the laser beam and the material surface defines the crater shape and size. As compared to other laser application robot based laser engraving process on non-metallic part allows short-time with precision based design where material damage should be minimal [27]-[29].

Now-a-days human robot communication has reintroduced a focus on the development of many industrial operations like laser engraving, laser drawing. It has received wide robot explorers to use robotics for a number of scenarios by facilitating the potential development of the web based robotic ecosystem. The uFactory [30] is specialized in developing and manufacturing consumer robotics systems aiming to make people believe that humanity is going to benefit from robots in our daily life, and that they will become a necessary item for everybody in the future. Moharana et al. [31] performed a high speed-based laser cutting based operation with parallel delta robot which gave a precise and satisfactory result in comparison to serial robots. Pollák and Dobránsky [32] used a robot to create different shapes using laser engraving process involving wood based soft materials. Engraving operation was conducted using software simulation based on defining robot arm movement without changing the laser beam concentration and maintaining a constant distance from the material surface at a predetermined distance [32].

In this paper, we have experimentally studied \& graphically represented the impact of robot operated laser nozzle engraving process on a wooden pitch board. The purpose of the study is to investigate how laser engraving parameters like spot diameter, depth of penetration change with the working length of robot end effector on a wooden pitch board surface.

\section{ROBOT TECHNICAL DETAILS}

The uArm Swift Pro robotic arm is Arduino-powered desktop 4-axis parallel-mechanism robot, which is extremely light. It's small, powerful and affordable for the beginners. For exquisite tasks like drawing and laser engraving, uArm Swift Pro is smooth and reliable. The uArm Swift Pro has better performance: Stepper motor with 12-bit encoder, customized gearbox with stepper motor and repeatability: $0.2 \mathrm{~mm}$. This arm consists of a base, manipulator and end-effector (here, laser nozzle is used for engraving purpose). The robot is basically of 4 DOF having 4 links out of which one is fixed one and 4 joints out of which 3 are rotational pair and 1 is prismatic pair. The working range of robotic arm is $50 \mathrm{~mm}$ to $320 \mathrm{~mm}$. Its working envelope is hollow cylindrical type. The uArm swift pro consists of 4 stepper motors for the movement of 4 joints, without any external position sensor. Both sides of the robot lower arm attached with left and right motor. Other motors are generally connected to base and end effector for the movement of uArm.

\section{EXPERIMENT DETAILS}

\subsection{Experimental set-up}

To conduct the experiment uArm Swift Pro Robot, hand screw, wooden pitch board $(12 \times 12 \mathrm{~cm})$ with $2.8 \mathrm{~mm}$ depth measured in electronic micrometer, uArm studio software such components are needed, see in Figure 1. It comprises of semiconductor type $0.5 \mathrm{~W}$ laser nozzle engraver which is attached at the end effector with the robot arm by six pin connector. At the head view, of the robot based engraving kit laser nozzle adjuster or knob is there which turns to focus the laser lens and at the tail view cooling fan turns when laser is on. The penetration depth and the spot diameter of laser beam on the board surface are measured with the help of LEICA MICROSCOPE (DM2500M). Initially before performing the task it is mandatory to check the zero point setup whether the robot assisted laser nozzle touches the pitch-board top surface or not. Then after ensuring the setup robot moves the arm and placed the end effector at a certain initial height of $13.8 \mathrm{~cm}$ measured from the wooden pitch board top surface \& set the engraving speed at $196 \mathrm{~mm} / \mathrm{sec}$. For performing engraving, robot software based firmware is ready to move its arm with laser nozzle by 6 pin connector. Laser beam gave off a violet glow, when it looked from laser safety goggles. Finally, the robot arm with the laser nozzle returns to its original location to complete the process. A wellfocused laser lens leaves dark burn marks and an unfocused lens leaves an irregular outline. Focusing the lens can be difficult as anyone have to tune with fingers and avoid them getting into the line of fire. 
Laser Engraving and drawing share the same graphical interface. For the first time laser engraving, adjust the zero point and focus the laser beam at the target material. Zero point adjustment means placing the end effector (laser nozzle) to the work piece surface where it is going to engrave. Basically, the zero point does not contain zero value as it ensures that the laser nozzle just touches the target surface. In this experiment zero point has been set to $50 \mathrm{~mm}$ which is the default value. There are two types of engraving pattern available in uArm studio i.e. grayscale and outline. For outline mode, robot performs only the outer section engraving of the pattern but in grayscale mode full pattern engraving is possible. For better view experiment can be performed in grayscale mode. The required pattern (here text) should be inserted at a specified position within the marks $\mathrm{A}$ and $\mathrm{C}$ as in Figure 2 and Figure 3. If the pattern is put below A or too close to the mark $\mathrm{C}$ then the laser does not work or even the engraving will stop. The properties of material for laser engraving and the technical specifications of the laser engraving kit is shown in Table 1.

Table 1. Material properties and laser engraving kit technical specifications

\begin{tabular}{l} 
Material used: wooden pitch board \\
\hline Length and breadth of material: $12 \mathrm{~cm} \times 12 \mathrm{~cm}$ \\
Material thickness: $2.8 \mathrm{~mm}$ \\
Maximum working range of the robot end-effector: $320 \mathrm{~mm}$ \\
Engraving Speed: $196 \mathrm{~mm} / \mathrm{sec}$ \\
Laser Power: $0.5 \mathrm{~W}$ (fixed) \\
Working V \& I: $12 \mathrm{~V}, 5 \mathrm{~A}$ (fixed) \\
Wavelength: $405 \mathrm{~nm}$ (fixed) \\
\hline
\end{tabular}

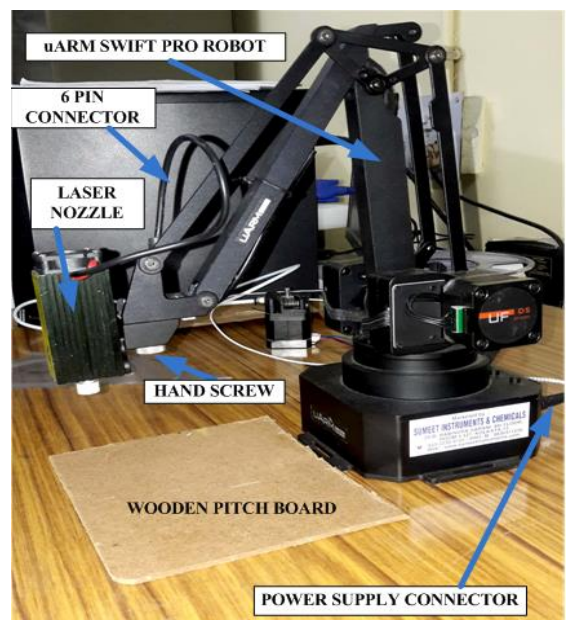

Figure 1. Experimental setup

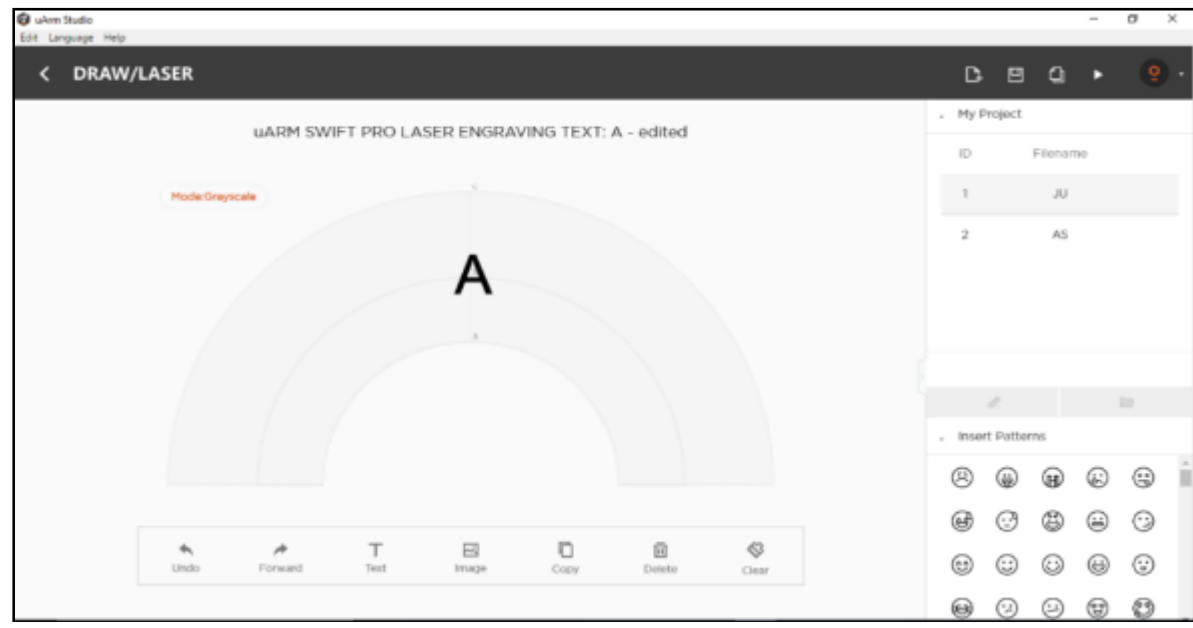

Figure 2. Position of $1^{\text {st }}$ pattern close to the mark ' $B$ ' between the marks ' $A$ ' and ' $C$ ' 


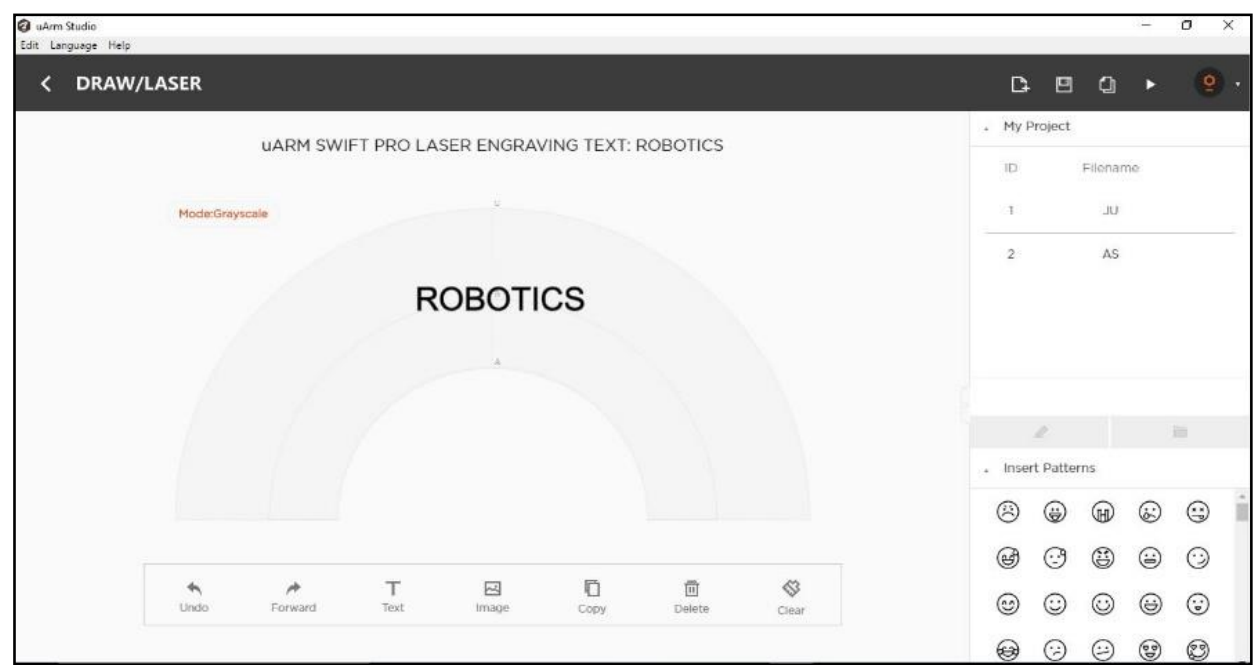

Figure 3. Position of $2^{\text {nd }}$ pattern close to the mark ' $B$ ' between the marks ' $A$ ' and ' $C$ '

\subsection{Robot based laser engraving experiment procedure}

Before performing laser engraving, when the laser power is off which is shown in Figure 4(a), indicates the uArm robot is in standalone mode as shown in Figure 5(a). During laser engraving operation the laser power is on which is shown in Figure 4(b), the robot moves its arm gradually to perform the required task as shown in Figure 5(b). Laser beam adjuster or knob, this adjuster as shown in Figure 6 consists of lens and thread inside so that we can adjust the laser beam. The threaded portion of the body is of $8 \mathrm{~mm}$ which has the pitch length of $0.666 \mathrm{~mm}$. In the threaded body there is black mark. Above the black mark the thread portion is of $1.998 \mathrm{~mm}$ and the following mark the threaded portion is of $6.002 \mathrm{~mm}$. The whole body of the adjuster (knob) is knurled out so that the gripping may be easy.

Threaded length: $8 \mathrm{~mm}$

No. of thread division: 12

Pitch length $=$ Total threaded length/No. of threaded division

$$
\begin{aligned}
& =8 / 12 \mathrm{~mm} \\
& =0.666 \mathrm{~mm}
\end{aligned}
$$

Therefore, pitch length of the thread is of $0.0666 \mathrm{~cm}$

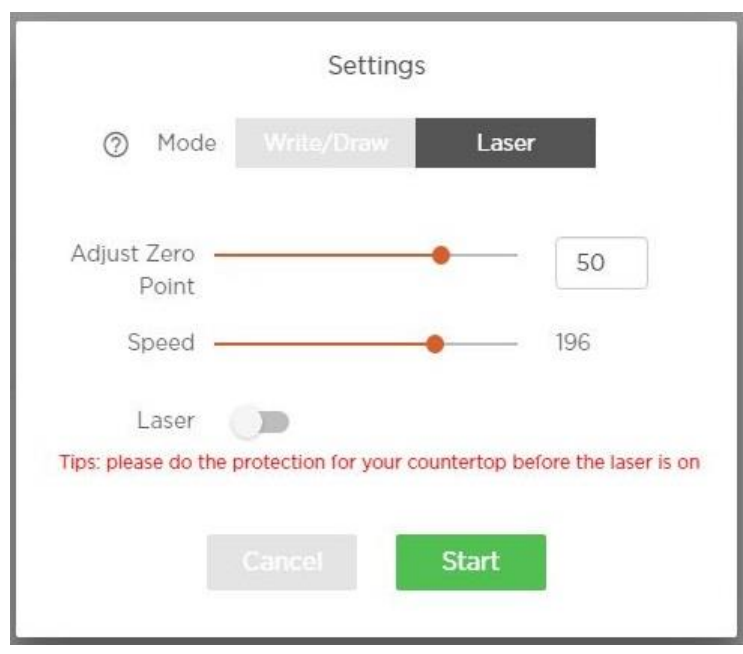

(a)

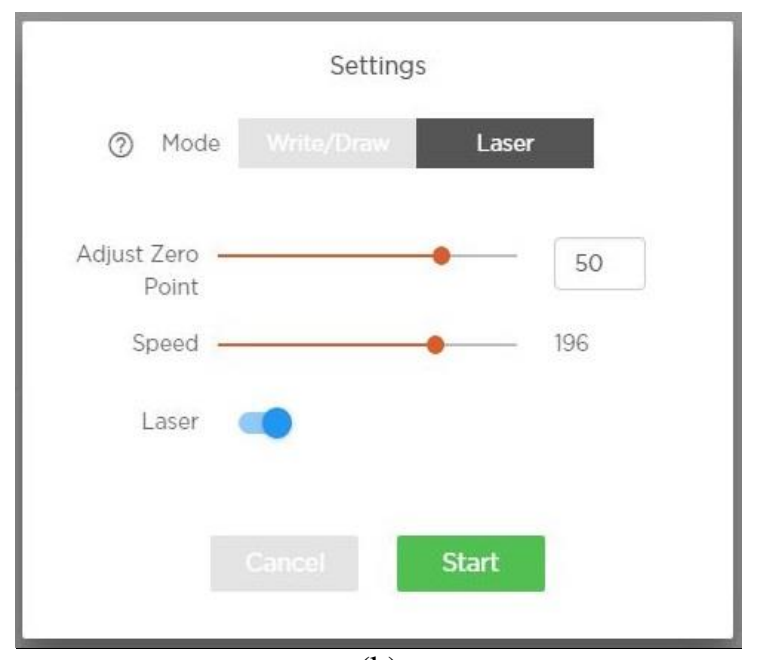

(b)

Figure 4. Laser engraving: (a) laser power off condition before engraving start, (b) laser power on condition during engraving shows in the uArm studio software 


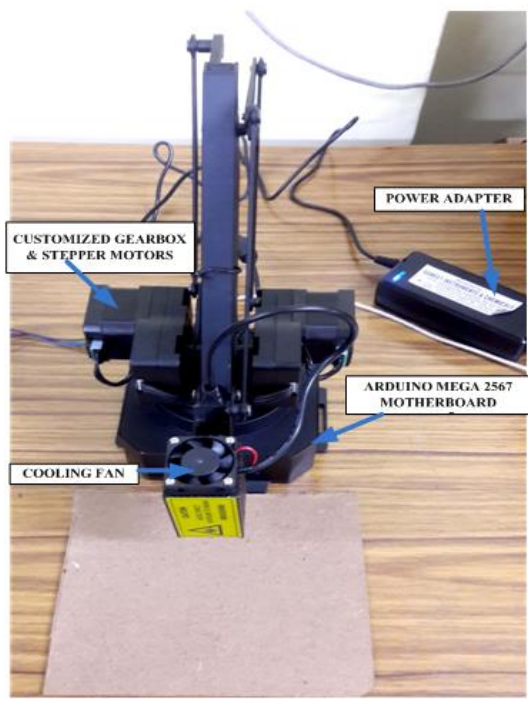

(a)

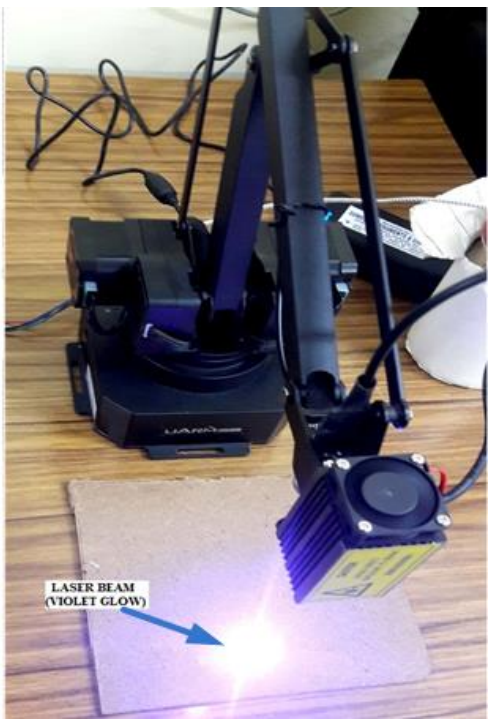

(b)

Figure 5. uArm Robot standalone at initial position: (a) before laser operation and Robot arm movement, (b) during laser engraving process
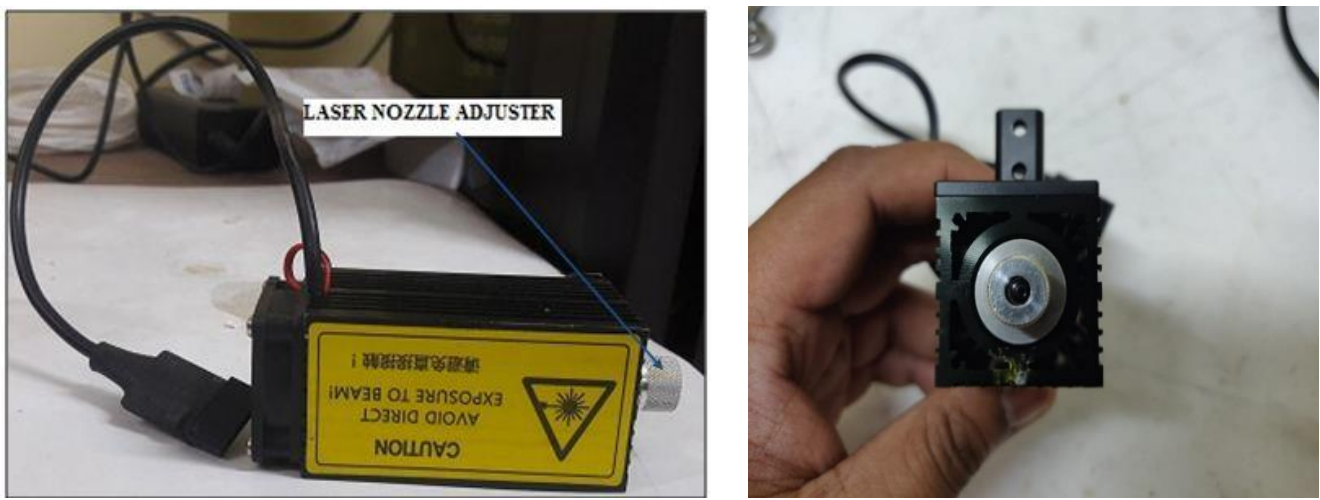

Figure 6. Side and top view of laser nozzle adjuster or knob

\subsection{Robot based laser engraving experiment flowchart}

After installing the uArm Studio 1.1.22 version software the laser nozzle is attached with the robot end effector and turned on the power supply. Connector wires enable the robot to communicate directly with the software firmware by connector wires. Initially, the picture pattern has been drawn in the sotware. The software play button is pressed to begin the engraving operation. According to the condition, the robot operated laser beam will form the same pattern on the material surface after adjusting zero point. The robot assisted laser engraving process flowchart is shown in Figure 7.

\section{RESULTS AND DISCUSSION}

The effects of laser beam spot diameter and depth of penetration with change in working length of the robot end effector (laser nozzle) from wooden pitch board top surface has been measured experimentally. When the laser beam strikes on the wooden board as shown in Figure 8 then working length of the robot end effector: $14.180 \mathrm{~cm}$, depth of penetration: $0.066 \mathrm{~mm}$, spot diameter: $1.6845 \mathrm{~mm}$. When the laser beam penetrates on the wooden board as shown in Figure 9 then working length of the robot end effector: 14.2131 $\mathrm{cm}$, depth of penetration: $0.1271 \mathrm{~mm}$, spot diameter: $1.3636 \mathrm{~mm}$. As the laser beam penetrates maximum on the wooden board as shown in Figure 10 then working length of the robot end effector: $14.2318 \mathrm{~cm}$, depth of penetration: $0.1826 \mathrm{~mm}$, spot diameter: $1.3749 \mathrm{~mm}$. 


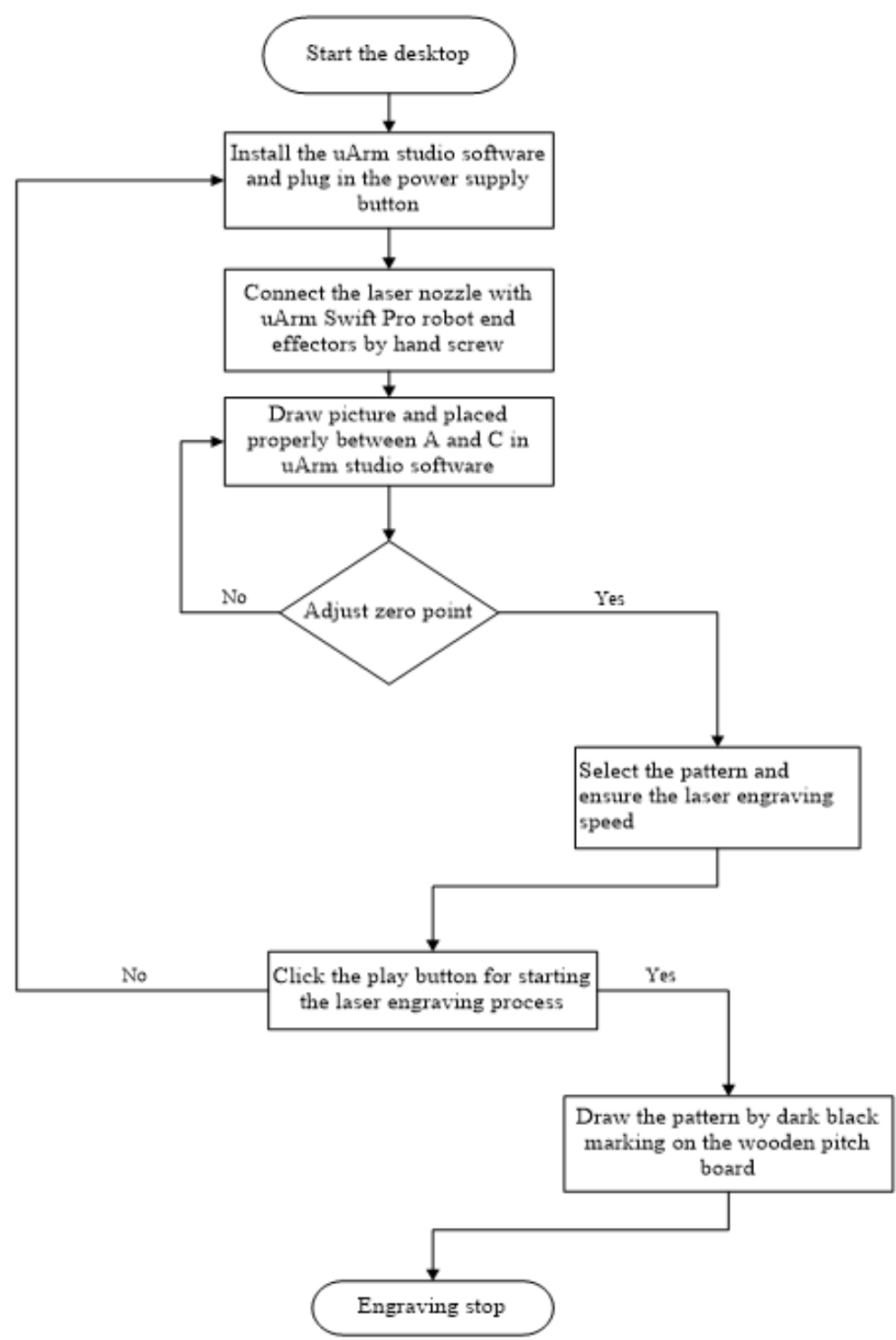

Figure 7. Flowchart framework for robotic laser engraving process

The above deep engraving pattern Figure 11 has been formed by uArm swift pro robot assisted laser engraving tool with a working length of $14.2318 \mathrm{~cm}$. The operating time, which is measured by stopwatch, is around $8 \mathrm{~min}$. Similarly, the light engraving pattern Figure 12 has been formed by uArm swift pro robot assisted laser engraving tool with a working length of $14.180 \mathrm{~cm}$. The operating time, which is measured by stopwatch, is around $46 \mathrm{~min}$. For both engraving operations the robot operated laser engraving tool movement speed is $196 \mathrm{~mm} / \mathrm{sec}$.

According to the different working length of uARM end effector laser beam focus has been identified as shown in Table 2. It has been clearly shown that initially when the end effector (laser engraving tool) working length of uARM Swift Pro Robot certain changes from 14.6 to $14.1132 \mathrm{~cm}$, the laser beam focus diverges without concentration on the wooden-board thus no marking or no penetration occurs which also effects on the statistical parameter. For the 14.6 to 14.1132 working length the Skewness value is 0.3279 and the variance is $6.93 \times 10^{-4}$, from the Table 3. Performing engraving operation robot end effector (laser engraving tool) laser beam focus is set up by the laser adjuster. At the working length of $14.180 \mathrm{~cm}$ the laser beam strikes the wooden board and light engraving pattern has been formed as shown in Figure 12. The spot diameter of the laser against the working length is shown in Figure 13. For better engraving operation the adjuster set at a fine convergence point in the working length of $14.2318 \mathrm{~cm}$ and deep engraving pattern has been formed as shown in Figure 11. The depth of penetration of the laser against the working length is shown in Figure 14. The deep engraving operation on the wooden-board only performs after penetrates the 
wooden-board and at that time the working length is $14.2131 \mathrm{~cm}$. From the beam strike to maximum dissemination the statistical parameter Skewness gives positive value i.e. 0.6951 and the variance shows the value 0.0739 . But after the maximum convergence of laser beam and the rotation of the beam adjuster when the robot reaches the length of $14.4462 \mathrm{~cm}$ the beam becomes wide and at a $14.5794 \mathrm{~cm}$ length maximum divergence occurs thus there has no penetration. In this divergence range the skewness value again comes in negative and variance is comparatively small.

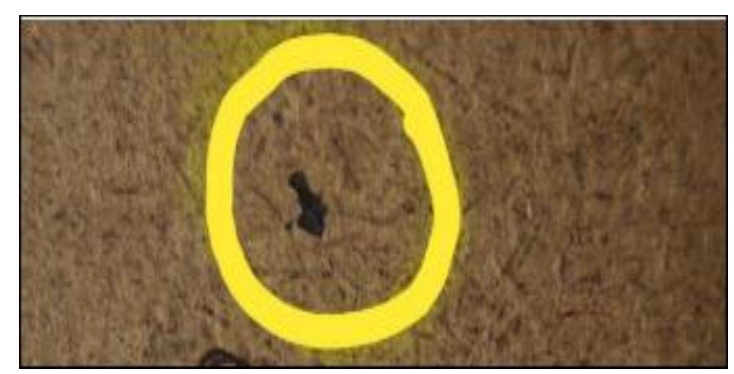

Figure 8. Laser beam from robot assisted laser engraving tool (laser nozzle) strikes on the wooden board

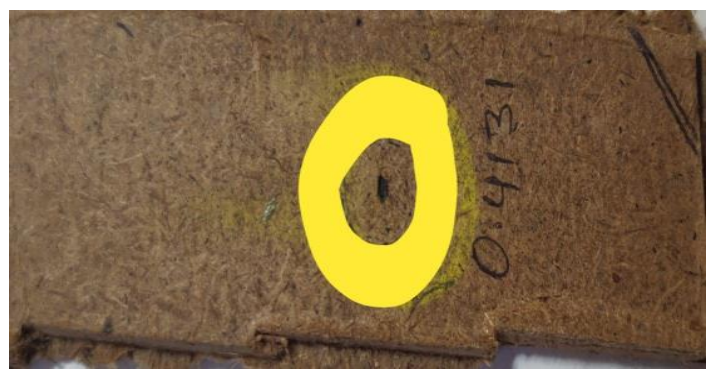

Figure 9. Penetration occurs on the wooden board by robot assisted laser engraving tool

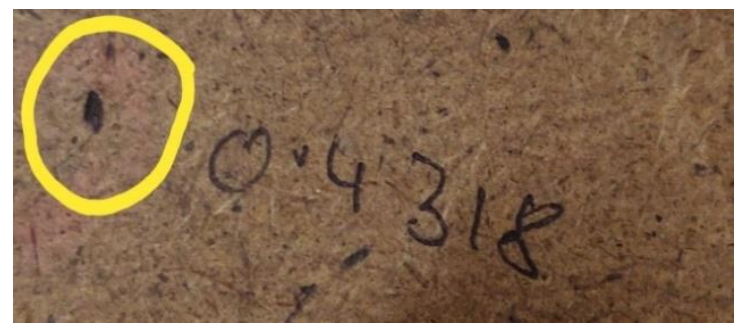

Figure 10. Maximum penetration occurs the wooden board by robot assisted laser engraving tool

Table 2. Experimental study of laser beam focus according to the working length of uArm end effector and pitch length of laser adjuster

\begin{tabular}{|c|c|c|}
\hline $\begin{array}{l}\text { Initial length of the robot end } \\
\text { effector (laser nozzle) from pitch } \\
\text { board top surface L1 }(\mathrm{cm})\end{array}$ & $\begin{array}{l}\text { Working length of the robot end effector (laser } \\
\text { nozzle) from pitch board top surface L2 }(\mathrm{cm})\end{array}$ & $\begin{array}{l}\text { Pitch length of the thread on laser } \\
\text { adjuster knob } \Delta \mathrm{l}=(\mathrm{L} 2-\mathrm{L} 1) \mathrm{cm}\end{array}$ \\
\hline 13.8 & $\begin{array}{c}14.6 \\
14.1466 \\
14.1132 \\
14.180 \\
14.2131 \\
14.2318 \\
14.2464 \\
14.313 \\
14.3796 \\
14.4462 \\
14.5128 \\
14.5794 \\
\end{array}$ & $\begin{array}{c}0.80 \\
0.3466 \\
0.3132 \\
0.3798 \\
0.4131 \\
0.4318 \\
0.4464 \\
0.513 \\
0.5796 \\
0.6462 \\
0.7128 \\
0.7794 \\
\end{array}$ \\
\hline
\end{tabular}


Table 3. Effect of statistical parameter on working length of the robot end effector

\begin{tabular}{ccc}
\hline Kurtosis & Skewness & Variance \\
\hline 1.5 & -0.3279 & $6.93 \times 10^{-4}$ \\
1.5 & 0.6951 & 0.0739 \\
1.5 & $-4.89 \times 10^{-4}$ & 0.0044 \\
\hline
\end{tabular}

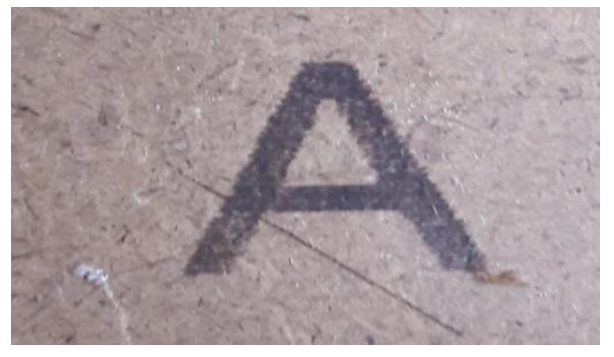

Figure 11. Deep engraving pattern forms

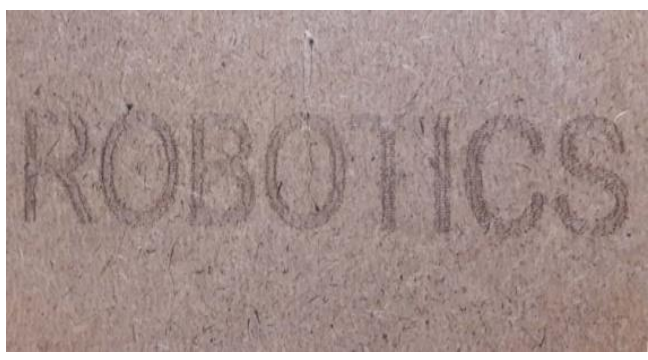

Figure 12. Light engraving pattern forms

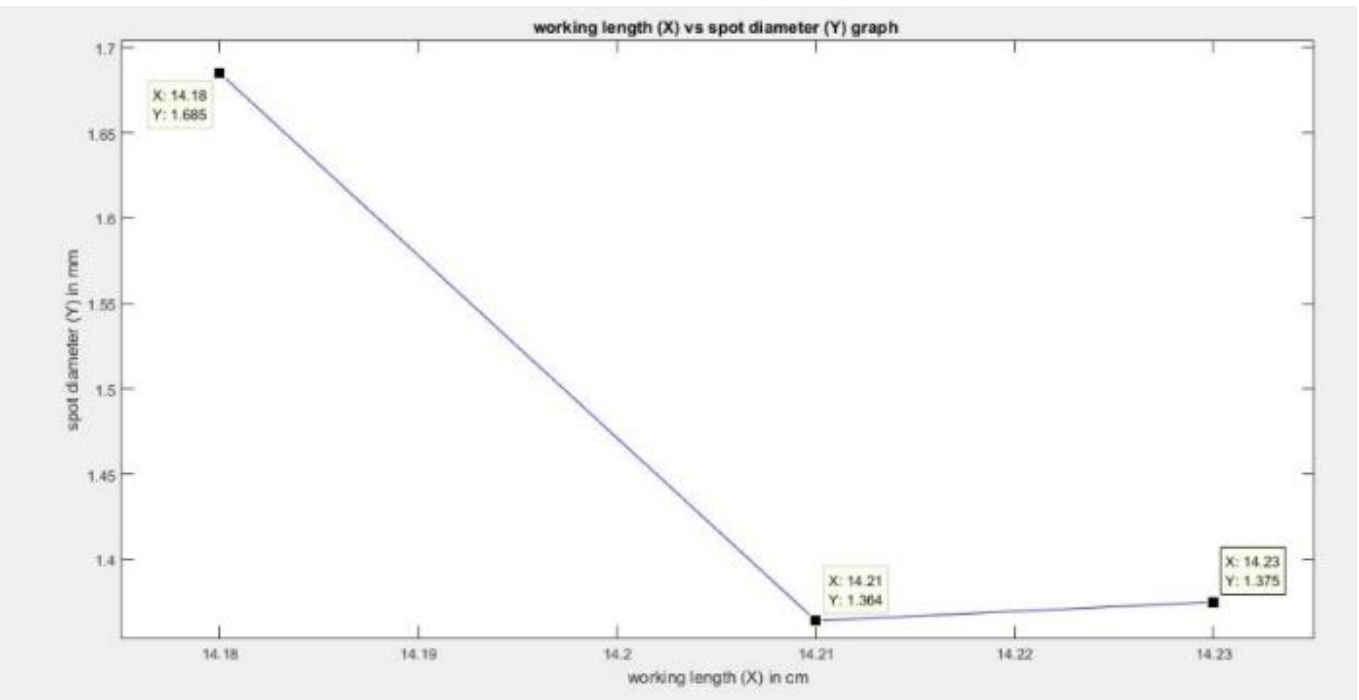

Figure 13. Graph showing the spot diameter of the laser against the working length

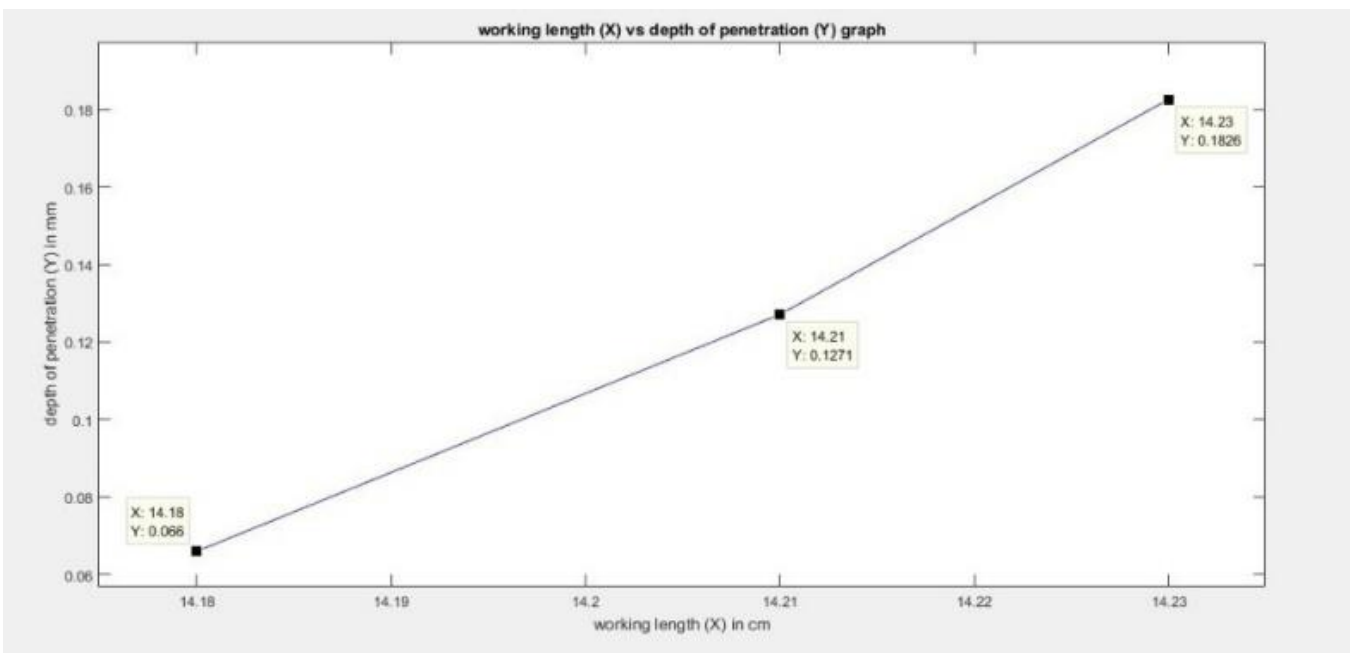

Figure 14. Graph showing the depth of penetration of the laser against the working length 


\section{CONCLUSION}

In this paper, uArm robot operated laser beam engraving effect on the wooden pitch board has investigated. The experimental study shows that when the working length of robot operated laser nozzle from the material surface increases, the depth of penetration also increases with a decrease of spot diameter. The research will give satisfactory results for robot end effector working lengths in the range of $14.180-14.2318 \mathrm{~cm}$. Since the laser beam gets more concentrated at the proposed working length of the robot end effector with an increase in ablation rate, giving the most prominent depiction. Future research work will reveal the algorithm based mathematical relationship between the laser engraving parameter and the working length of laser nozzle for different types of non-metallic surface.

\section{REFERENCES}

[1] L. Reinprecht and Z. Vidholdová, "The Impact of a $\mathrm{CO}_{2}$ Laser on the Adhesion and Mold Resistance of a Synthetic Polymer Layer on a Wood Surface," Forests, vol. 12, no. 2, p. 242, 2021, doi: 10.3390/f12020242.

[2] M. Aniszewska, A. Maciak, W. Zychowicz, W. Zowczak, T. Mühlke, B. Christoph, S. Lamrini and S. Sujecki, "Infrared Laser Application to Wood Cutting," Materials, vol. 13, no. 22, p. 5222, 2020, doi: $10.3390 / \mathrm{ma1} 3225222$.

[3] M. Jurek and R. Wagnerová, "Laser beam calibration for wood surface colour treatment," European Journal of Wood and Wood Products, pp. 1-11, 2021, doi: 10.1007/s00107-021-01704-3.

[4] S. Fukuta, M. Nomura, T. Ikeda, M. Yoshizawa, M. Yamasaki, Y. Sasaki, "UV laser machining of wood," European journal of wood and wood products, vol. 74, pp. 261-267, 2016, doi: 10.1007/s00107-016-1010-9.

[5] I. Kubovský, L'. Krišták, J. Suja, M. Gajtanska, R. Igaz, I. Ružiak and R. Réh, "Optimization of Parameters for the cutting of Wood-Based Materials by a $\mathrm{CO}_{2}$ Laser," Applied Sciences, vol. 10, no. 22, p. 8113, 2020, doi: 10.3390/app10228113.

[6] J. Kúdela, L. Reinprecht, Z. Vidholdová, M. Andrejko, "Surface properties of beech wood modified by a CO2 laser," Acta Facultatis Xylologiae Zvolen, vol. 61, no. 1, pp. 5-18, 2019, doi: 10.17423/afx.2019.61.1.01.

[7] T. Jiang, C. Yang, Y. Yu, B.S. Doumbia, J. Liu, Y. Ma, "Prediction and Analysis of Surface Quality of Northeast China Ash Wood during Water-Jet Assisted CO2 Laser Cutting," Journal of Renewable Materials, vol. 9, no. 1, pp. 119-128, 2021, doi: 10.32604/jrm.2021.011490.

[8] K.C. Yung, H.S. Choy, T. Xiao, Z. Cai, "UV laser cutting of beech plywood," The International Journal of Advanced Manufacturing Technology, vol. 112, pp. 925-947, 2021, doi: 10.1007/s00170-020-06376-6.

[9] J. C. Ion, Laser processing of engineering materials, principles, procedure and industrial application, edizione. Butterworth-Heinemann Ltd, 2005, p. 556.

[10] J.F. Ready, D.F. Farson, T. Feeley, LIA handbook of laser materials processing, Berlin and Heidelberg GmbH \& Co. K: Springer, 2001, p. 803.

[11] A. N. Bakhtiyari, Z. Wang, L. Wang and H. Zheng, "A review on applications of artificial intelligence in modelling and optimization of laser beam machining," Optics \& Laser Technology, vol. 135, p. 106721, 2021, doi: 10.1016/j.optlastec.2020.106721.

[12] P. Stavropoulos, A. Papacharalampopoulos and L. Athanasopoulou, "A molecular dynamics based digital twin for ultrafast laser material removal processes," The International Journal of Advanced Manufacturing Technology, vol. 108, pp. 413-426, 2020, doi: 10.1007/s00170-020-05387-7.

[13] D. Hellrung, A. Gillner, R. Poprawe, "Laser beam removal of micro-structures with Nd: YAG lasers," Lasers in Material Processing. SPIE, vol. 3097, pp. 267-273, 1997, doi: 10.1117/12.281085.

[14] H.J. Booth, "Recent applications of pulsed lasers in advanced materials processing," Thin Solid Films, vol. 453454, pp. 450- 457, 2004, doi: 10.1016/j.tsf.2003.11.130.

[15] M. Gaff, F. Razaei, A. Sikora,Š. Hysek,M. Sedlecký, G. Ditommaso, R. Corleto, G. Kamboj, A. Sethy, M. Vališ, K. Řipa, "Interactions of monitored factors upon tensile glue shear strength on laser cut wood," Composite Structures, vol. 234, pp. 1-10, 2020, doi: 10.1016/j.compstruct.2019.111679.

[16] R. Li, C. He, Y. Chen and X. Wang, "Effects of laser parameters on the width of color change area of poplar wood surface during a single irradiation," European Journal of Wood and Wood Products, pp. 1-8, 2021, doi: 10.1007/s00107-021-01706-1.

[17] J.A. Dolan, "Characterization of Laser Modified Surfaces for Wood Adhesion," M.S. thesis, Virginia Polytechnic Institute and State University, USA, 2014.

[18] M. Ozdemir and H. Sadikoglu, "A new and emerging technology: Laser-induced surface modification of polymers," Trends in Food Science \& Technology, vol. 9, no. 4, pp. 159-167, 1998, doi: S0924-2244(98)00035-1.

[19] C. Leone, V. Lopresto, I. De. Iorio, "Wood engraving by Q-switched diode-pumped frequency-doubled Nd: YAG green laser," Optics and Lasers in Engineering, vol. 47, no. 1, pp. 161-168, 2009, doi: 10.1016/j.optlaseng.2008.06.019.

[20] M. Panzner, G. Wiedemann, K. Henneberg, R. Fischer, T. Wittke, R. Dietsch, "Experimental investigation of the laser ablation process on wood surfaces," Applied Surface Science, vol. 127-129, pp. 787-792, 1998, doi: S01694332(97)00743-5.

[21] M. Castillejo, M. Martin, M. Oujja, E. Rebollar, C. Domingo, J. V. G. Ramos, S. S. Cortes, "Effect of wavelength on the laser cleaning of polychromes on wood," Journal of Cultural Heritage, vol. 4, no. 3, pp. 243-249, 2003, doi: S1296-2074(03)00049-9. 
[22] S. Carlquist, Comparative wood anatomy systematic, ecological and evolutionary aspects of dicotyledon wood, Springer series in wood science, 2001.

[23] S. Barcikowski, G. Koch, J. Odermatt, "Characterisation and modification of the heat affected zone during laser material processing of wood and wood composites," HolzalsRoh- und Werkstoff, vol. 64, pp. 94-103, 2006, doi: 10.1007/s00107-005-0028-1.

[24] A.K. Dubey, V. Yadava, "Laser beam machining- A review," International journal of Machine Tools and Manufacture, vol. 48, no. 6, pp. 609-628, 2008, doi: 10.1016/j.ijmachtools.2007.10.017.

[25] A. Kaldos, H.J. Pieper, E. Wolf, M. Krause, "Laser machining in die making- a modern rapid tooling process," Journal of Materials Processing Technology, vol. 155-156, pp. 1815-1820, 2004, doi: 10.1016/j.jmatprotec.2004.04.258.

[26] S. Kasman, "Impact of parameters on the process response: A Taguchi orthogonal analysis for laser engraving," Measurement, vol. 46, no. 8, pp. 2577-2584, 2013, doi: 10.1016/j.measurement.2013.04.022.

[27] F. Ferrero, F. Testore, C. Tonin, R. Innocenti, "Surface degradation of linen textiles induced by laser treatment: comparsion with electron beam and heat source," AUTEX Research Journal, vol. 2, no. 3, pp. 109-114, 2002.

[28] V. N. Wijayathunga, C. A. Lawrence, R. S. Blackburn, M. P. U. Bandara, E. L. V. Lewis, H. M. El-Dessowky and V. Cheung, "Influence of laser irradiation on the optical and structural properties of poly (ethylene terephthalate) fibres," Optics \& Laser Technology, vol. 39, no. 7, pp. 1301-1309, 2007, doi: 10.1016/j.optlastec.2006.12.007.

[29] Y. W. Yip, K. Chan, K. M. Sin, K. S. Lau, "Formation of periodic structures by surface treatments of polyamide fiber. Part I. UV excimer laser irradiation," Applied Surface Science, vol. 253, no. 5, pp. 2637-2643, 2006, doi: 10.1016/j.apsusc.2006.05.037.

[30] M. Saboia, V. Thangavelu, W. Gosrich, N. Napp, "Autonomous adaptive modification of Unstructured Environments," Proceedings of Robotics: Science and Systems, 2018, doi: 10.15607/RSS.2018.XIV.070.

[31] B. Moharana, R. Gupta, B. K. Kushwaha, "Optimization and design of a laser-cutting machine using delta robot," International Journal of Engineering Trends and Technology (IJETT), vol. 10, no. 4, pp. 176-179, 2014, doi: 10.14445/22315381/IJETT-V10P233.

[32] M. Pollák and J. Dobránsky, "Structural Design and Material Cutting Using a Laser End Effector on a Robot Arm," Tem Journal, vol. 9, no. 4, pp. 1455-1459, 2020, doi: 10.18421/TEM94-17.

\section{BIOGRAPHIES OF AUTHORS}
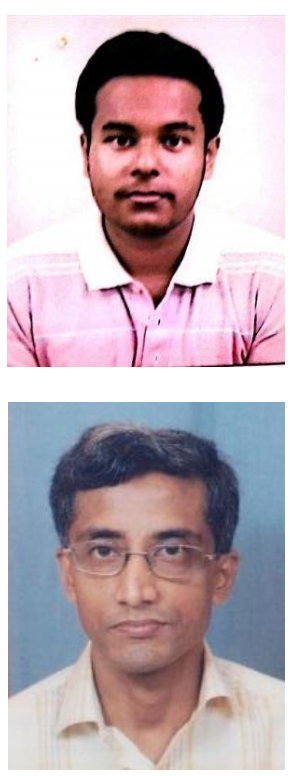

Soumen Mondal received B.Tech degree in Mechanical Engineering in 2016, M.Tech degree in Manufacturing Systems Engineering in 2018. He is currently pursuing Ph.D. from Jadavpur University, India. His research interests are 3D Printing Robot, Robot Assisted Laser Engraving, Robot Vision System, and Signal Processing.

Dr. Ajoy Kumar Dutta is currently a Professor in the Department of Production Engineering, Jadavpur University, INDIA. He received his B. E. \& M. E. degrees in Electronics \& Telecommunication Engg from Jadavpur University in 1983 \& 1985 respectively, and Ph. D. (Engg) degree in the area of Robotics from Jadavpur University in 1991. His Field of Specialization and Research Area are Robotics, Sensors, Computer Vision, Microprocessor Applications, and Mechatronics. He has teaching \& research experience of 31 years. 